\title{
AN OCCLUDER FOR SQUINT
}

BY

\section{A. RUGG-GUNN}

LONDON

A Reliable occluder plays an important, and, in most cases, an indispensable part in the early treatment of concomitant convergent strabismus. With the exception of the alternating type, every constantly squinting eye sooner or later acquires amblyopia in the central area of the visual field and loses the power of central fixation. Re-education of this amblyopic area is notoriously difficult even after the need to suppress the image is removed from the squinting eye by correcting glasses.

Many varieties of occluder, aiming at total occlusion of the better eye, have been devised, but nearly all reveal in practice some defect which invalidates their use. The better eye also is capable of exercising remarkable ingenuity in outwitting an occluder. Even when total occlusion has been successfully attained, several practical objections may be present. Either the appearance is unsightly and disliked by the parents ; or ventilation is inadequate ; or the mental effect, which may sometimes approximate to terror, of nearly blinding the child by depriving it of its only functioning eye, may be so unpleasant that it is impossible to continue its use. Above all, beneath the occluder the eye assumes the squinting position and convergence remains undisturbed.

Usually total occlusion is not attained. The better eye can be depended upon to discover very quickly the occluder's weak points and to find some means for maintaining vision. This surreptitious vision is usually carried on, with the aid of a tilt of the head, in the worst possible position; viz.: extreme convergence, through a minute space which appears between the edge of the occluder and the bridge of the nose.

The principle of complete occlusion hitherto generally observed does not appear to be necessary or even desirable. In the following description of an occluder it will be found that this principle has been dispensed with and the disadvantages enumerated above disappear. The design (Fig. 1 ) is very simple. It consists of two parts-a " half lens " of Chavasse glass which covers rather more than the nasal half of the spectacle lens, behind which it is worn, and a rubber projection which can be trimmed where necessary to fit into the inner aspect of the orbit.

Chavasse glass has one surface plain and the other mottled, the effect being to permit a perfectly clear view of the eye while at the same time vision is reduced to $6 / 60$ ths or less.

The temporal rim of the occluder is straight and forms a vertical 
line which should coincide with the temporal margin of the pupil in ordinary daylight or about $2 \mathrm{~mm}$. to the temporal side of the optical centre of the spectacle lens. The remainder of the rim is

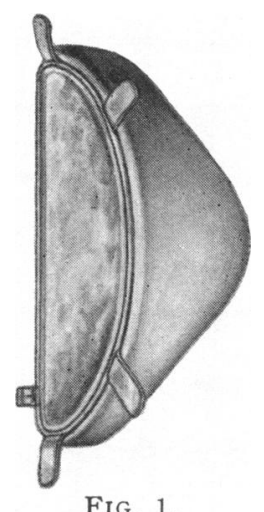

FIG. 1.

curved and follows that of the spectacle frame but has a projecting margin of rubber designed to fit accurately into the nasal side of the orbit and rest against the bridge of the nose. The rubber margin is easily trimmed by means of scissors to the required shape and its deepest part ought to touch the inner canthus. The

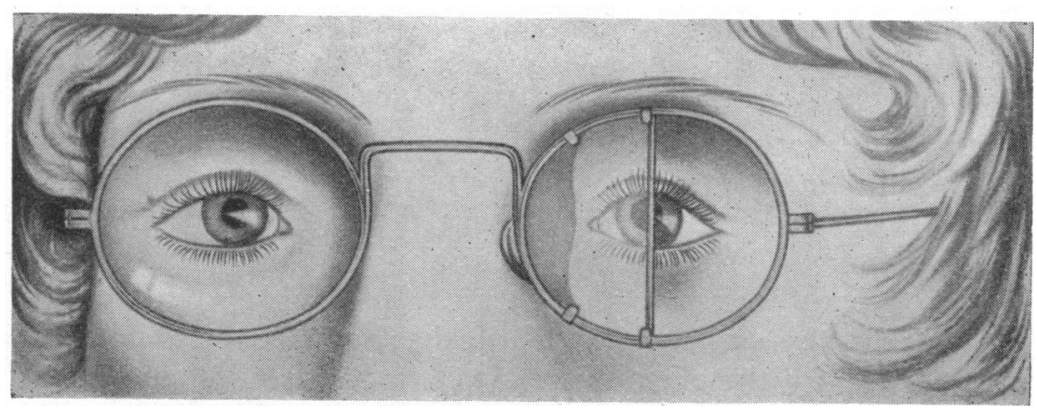

FIG. 2.

object of the projection is to block up the space between the nose and the spectacle frame. Four soft metal clips help to clamp the occluder to the back or ocular surface of the spectacle lens. The rubber margin is sufficiently pliable to accommodate spectacle bridges both of the ordinary and "scholar" type.

The occluder (Fig. 2) when worn, is almost invisible. Central vision with the better eye is still possible, especially when the head is tilted slightly to the other side, but it is only possible in the position of outward deviation, that is, of relaxed convergence. 
In all other positions only the peripheral field or least sensitive part of the occluded eye can function. As the acquired amblyopia of squint is confined to the central retinal area, peripheral vision in the two eyes is practically equal and becomes obviously so to the patient under the new conditions imposed by the occluder. As a result suppression of the visual images in the squinting eye is less likely to occur. As another result free movement of the squinting eye is encouraged. This is an important step towards establishing binocular vision, for the difficulty of overcoming the relative immobility of a squinting eye is second only to that of overcoming its amblyopia. The simultaneous use of both eyes becomes possible in all positions and the way prepared for ultimate bimacular fixation.

Further, in the only position in which macular vision is permitted to the better eye, that is, in abduction, both visual axes approximate to parallelism. This is important, because, not only is convergence relaxed in this position, but retinal images become placed on relatively corresponding points. Thus the original motive for suppression is removed. Complete correspondence of retinal points does not seem to be necessary for bi-macular fixation, as psychical fusion helps to overcome minor amounts of discrepancy.

The association between spasm of accommodation and excessive convergence is attacked at two different points. Correcting lenses relax accommodation and along with it undue convergence, while inability to use the macula except in the position of least convergence helps further to break down excess of the latter and perhaps thus, secondarily, relieves accommodative spasm.

The occluder should be worn continuously over the better eye and the progress of the squinting eye tested from time to time in the usual way. The same device, slightly modified, may be used for concomitant divergent strabismus. It should in that condition be fitted on the temporal side of the better eye. There is a temptation to try the effect of two in divergent squint, one on each temporal half, but the effect is to encourage alternating suppression and a better result is obtained with only one.

\section{Summary}

(1) The occluder may be said to be practically invisible.

(2) It permits central vision of the occluded eye only in the position of relaxed convergence.

(3) It emphasizes the relative equality of peripheral vision in the two eyes, encouraging more reliance on the squinting eye and thus-

(a) discourages its desire for suppression,

(b) overcomes its relative immobility. 
(4) It encourages a position of the visual axes in which images fall on relatively corresponding points.

(5) By relaxing excessive convergence it may secondarily relieve accommodative spasm.

The makers of the occluder are Messrs. Theodore Hamblin, Ltd., 15, Wigmore Street, W. to whom my thanks are due for skilfully carrying out my suggestions.

\title{
THE FIELDS OF VISION IN MINERS' NYSTAGMUS
} BY

\author{
G. F. HAYCRAFT \\ WOLVERHAM PTON
}

IN the Ophthalmoscope, Vol. XI, p. 727, writing on the fields of vision in miners' nystagmus Cridland reported a concentric contraction for white, blue and red with occasional interlacing of red and blue. In the majority of cases the fields for the different colours maintained their usual relative proportions. I have been unable to find any further reports on this subject.

I have recently examined the fields of vision in a series of 43 cases. Of these, 35 were old, and eight new cases. In the latter class I include those certified as suffering from the disease within the last six months.

The list of old cases was compiled as follows :-

\begin{tabular}{|c|c|c|c|c|c|}
\hline $\begin{array}{l}\text { Certified as } \\
\text { Miners' } \\
\text { Nystagmus }\end{array}$ & & & & & $\begin{array}{l}\text { Lmber of } \\
\text { Cases }\end{array}$ \\
\hline 1 year & $\ldots$ & $\ldots$ & $\ldots$ & $\ldots$ & 6 \\
\hline 2 years & $\ldots$ & $\ldots$ & .. & $\ldots$ & 6 \\
\hline 3 years & $\ldots$ & $\ldots$ & $\ldots$ & $\ldots$ & 3 \\
\hline 4 years & $\ldots$ & . . & $\ldots$ & $\ldots$ & 3 \\
\hline 5 years & $\ldots$ & $\ldots$ & $\ldots$ & $\ldots$ & 5 \\
\hline 6 years & $\ldots$ & $\ldots$ & $\ldots$ & .. & 3 \\
\hline 7 years & $\ldots$ & $\ldots$ & $\ldots$ & . & 1 \\
\hline 8 years & $\ldots$ & $\ldots$ & $\ldots$ & $\ldots$ & 3 \\
\hline 10 years & $\ldots$ & $\ldots$ & $\ldots$ & $\ldots$ & 1 \\
\hline${ }^{*} 12$ years & $\ldots$ & $\ldots$ & $\ldots$ & $\ldots$ & 1 \\
\hline${ }^{*} 15$ years & $\ldots$ & $\ldots$ & $\ldots$ & $\ldots$ & 2 \\
\hline \multirow[t]{2}{*}{ * 25 years } & $\ldots$ & ... & $\ldots$ & $\ldots$ & 1 \\
\hline & & otal & $\ldots$ & $\ldots$ & 35 \\
\hline
\end{tabular}

*These four men had resumed work underground for two or three periods of from 2 to 4 years. 